\title{
Epidemiological characteristics and influencing factors of fatal drowning in children under 5 years old in Hunan Province, China: case-control study
}

Zhiyu Liu ${ }^{1+}$, Fanjuan Kong ${ }^{1 \dagger}$, Lei Yin², Aihua Wang ${ }^{1}$, Lili Xiong ${ }^{1}$, Donghua Xie ${ }^{1}$, Lizhang Chen ${ }^{3^{*}}$ (D) and Xiaoqi Sheng ${ }^{4^{*}}$

\begin{abstract}
Background: Drowning is still the primary cause of death in children under 5 years old, however, little is known about the drowning of Hunan province children. This study identifies the previously unpublished incidence and characteristics of fatal drowning in children of Hunan Province, and provide a basis for formulating strategies for children's survival, development and protection.
\end{abstract}

Methods: Data were collected through sampling with the multistage stratified cluster. The case group included all fatal frowning children under 5 years old in 13 districts between October 2015 and September 2016. The control group was matched 1:1.The epidemic features and influencing factors of fatal drowning were analyzed retrospectively according to descriptive analysis, conditional univariate and multivariate logistic regression analysis.

Results: For children aged 0-4 years, the fatal drowning was 16.1/100000 in Hunan Province. Drowning rates were higher for boys than girls. The proportion of rural areas is much higher than that of urban areas. The 1-2 years agegroup was the highest of all age groups. Fatal drowning mainly occurred in summer. The three leading drowning locations were pond, ditch and well. Playing close to the water were the leading activities that preceded fatal drowning. Multivariate logistic regression analysis showed that: children with primary caregiver education in high school and above $(O R=0.05)$ have a lower risk of fatal drowning; children with full-time care $(O R=0.17)$ have a lower risk; children who received unintentional drowning safety education $(O R=0.23)$ have a lower risk of fatal drowning. Children who were always swimming or playing near the water in the past 6 months $(\mathrm{OR}=3.13)$ have a higher risk of fatal drowning.

Conclusion: The fatal drowning among children under 5 years is the result of the interaction of multiple factors. A significant number of child deaths could have been prevented if parents and other close relatives had been more concerned about the safety of their children. We should develop health education plans for villagers to warn them of the dangers of drowning and preventive measures.

Keywords: Fatal drowning, Epidemiological features, Influencing factors, Children under 5 years old

\footnotetext{
*Correspondence: liche4005@126.com; shenxq999@163.com

†Zhiyu Liu and Fanjuan Kong are authors contributed equally to this work.

${ }^{\dagger}$ Zhiyu Liu and Fanjuan Kong are authors share first authorship on this work.

${ }^{3}$ Department of Epidemiology and Health Statistics, Xiangya School of Public Health, Central South University, Changsha, Hunan Province, China

${ }^{4}$ Hunan Provincial Maternal and Child Health Care Hospital, Changsha, Hunan

Province, China

Full list of author information is available at the end of the article
}

(c) The Author(s). 2019 Open Access This article is distributed under the terms of the Creative Commons Attribution 4.0 International License (http://creativecommons.org/licenses/by/4.0/), which permits unrestricted use, distribution, and reproduction in any medium, provided you give appropriate credit to the original author(s) and the source, provide a link to the Creative Commons license, and indicate if changes were made. The Creative Commons Public Domain Dedication waiver (http://creativecommons.org/publicdomain/zero/1.0/) applies to the data made available in this article, unless otherwise stated. 


\section{Background}

Drowning is the process of experiencing respiratory impairment from submersion/immersion in liquid [1]. Respiratory injury is followed by breath-holding and involuntary laryngospasm that leads to hypercapnia, hypoxemia, and, if prolonged, respiratory or cardiorespiratory arrest $[2,3]$.

Globally, drowning is still the leading cause of death among children aged 1-4 years worldwide [4]. Drowning is also one of the top three causes of death among Chinese teenagers and children [5]. According to WHO estimates, about 112,000 people die from unintentional drowning in China each year [6]. In Hunan Province, the mortality rate of children under 5 years decreased from 20.4 per thousand in 2002 to 5.6 per thousand in 2016 , but in the past five years, drowning has been the leading cause of death for children under 5 years old. This is an important factor endangering the health and lives of children in this region [7, 8].

The intervention of children's drowning is urgent. However, most of the research on fatal drowning in World and China is based on current research, and there are few case-control studies. Hunan Province also lacks relevant reports.

Therefore, this study intends to use a 1:1 paired casecontrol study to understand the epidemiological characteristics and related influencing factors of fatal drowning in children under 5 years old in Hunan Province. The risk factors of drowning death of children under 5 years old in Hunan Province were discussed. To supplement and perfect the shortcomings of descriptive research, and this paper puts forward the intervention strategies and measures of child drowning in our province.

\section{Methods}

\section{Research object}

Hunan Province is located in southeastern China, with an area of $21.2 \mathrm{~km}^{2}$ and a population of 69.0 million, there are 123 counties (cities, districts) and 14 cities. The province is a water-oriented province with long and hot summers. There are 5341 rivers more than $5 \mathrm{~km}$, over 14,000 reservoirs, and numerous ponds in the province. Multistage stratified cluster sampling was adopted. The first stage was stratified according to the city, and the second stage was stratified according to the district. In the 11 cities, 13counties (cities, districts) of Hunan Province, all unintentional drowning cases with children under the age of 5 from October 1, 2015 to September 30, 2016 were collected from the Maternal and Child Health Information Direct Reporting Management System. According to the 1:1 matching method, children under 5 years old who had never experienced unintentional drowning in the previous year before the survey were selected as controls. The matching conditions were as follows: (1) The age difference between the case and control was within 6 months; (2) The control was the same gender as case; (3) The control was living in the same village (residential) committee or adjacent village (residential) committee; (4) The control was a healthy child without illness. When the control child met the above conditions, the child was included.

\section{Survey method}

The survey was conducted in four quarters. For each quarter, the staff of each district organized and reported the drowning death list of children under 5 years old through the network direct reporting system. The list is checked with the CDC, civil affairs, public security and other departments, and checked by spot checks at the provincial, municipal and county levels to ensure that the death list is accurate and reliable. Using a retrospective questionnaire survey, in the two quarters after the child's drowning, trained investigators were accompanied by a child care professional and the local village doctors to investigate the case and the primary caregiver of the control child. The questionnaire consisted of two parts. The first part was shared by the Children's Drowning Death Questionnaire and the Control Questionnaire, and included basic child condition, basic family condition and child care. The second part was unique to the Children's Drowning Death Questionnaire, which investigated the situation when drowning occurred.

\section{Statistical methods}

EpiData3.1 was used to build related databases, and data entry was done using double entry. Statistical analyses were performed using SPSS20.0. The main characteristics were described by the adoption rate and proportion of counting data, and the influencing factors were analyzed by logistic regression under the conditions of single factor (first $=0.10$ ) and multiple factors (first $=0.10$, second $=0.15$ ). The Cox regression model in the survival analysis was used to fit and calculate the corresponding $P$ value, OR value and OR value $90 \% \mathrm{CI}$.

\section{Results}

\section{General characteristics}

From October 1st, 2015 to September 30th, 2016, 85 cases of fatal drowning occurred in children under 5 years old in 13 counties (cities, districts) of Hunan Province. A total of 79 cases were investigated in the study. 6 cases were not investigated because the caregivers did not cooperate or went out to work. The survey rate was 92.9\% (79/85). During the investigation period, the prevalence of fatal drowning in children under 5 years in Hunan Province was 16.1/100,000(Table 1). 
Table 1 Incidence of fatal drowning in children under 5 years old in Hunan Province

\begin{tabular}{lllll}
\hline Counties (cities, districts) & $\begin{array}{l}\text { Under } 5 \text { years } \\
\text { Old child }\end{array}$ & The number of drowning (investigation) & The number of drowning (actual) & Incidence rate(1/100,000) \\
\hline Liuyang & 97,958 & 6 & 6 & 6.1 \\
Hetang & 13,696 & 2 & 2 & 14.6 \\
Lusong & 13,940 & 5 & 5 & 35.9 \\
Shifeng & 15,963 & 1 & 2 & 12.5 \\
Xiangxiang & 53,213 & 18 & 18 & 33.8 \\
Leiyang & 64,706 & 12 & 14 & 21.6 \\
Pingjiang & 63,702 & 9 & 9 & 14.1 \\
Anxiang & 21,694 & 6 & 6 & 27.7 \\
Anhua & 64,673 & 3 & 4 & 6.2 \\
Guiyang & 44,046 & 8 & 8 & 18.2 \\
Xintian & 23,109 & 1 & 3 & 13.0 \\
Zhijiang & 22,108 & 4 & 4 & 18.1 \\
Yongshun & 30,314 & 4 & 4 & 13.2 \\
Total & 529,122 & 79 & 85 & 16.1 \\
\hline
\end{tabular}

\section{Epidemiological characteristics}

During the investigation period (Table 2), a total of 51 boys and 28 girls fatally drowned. The majority of drowning events occurred in toddlers aged 1-2 years who made up $43.0 \%$. The lowest proportion was in the 0-1 year who made up 5.1\%. Summer showed consistently higher frequency patterns for all drowning deaths (40.51\%).July was the month that drowning events most commonly occurred(19.0\%), but he number of occurrences in January was the least(3.8\%). Most fatal drownings $(93.7 \%)$ occurred in rural areas.

The top five fatal water types were ponds, ditches, wells, reservoirs and open pits. The most important activity of children before the occurrence of fatal drowning was playing close to the water, followed by playing in the water and slipping when wading.One case occurred in the bath, and one case fell from the second floor of the house that was opened to the pit. Most of the children's death sites were in the places where the drowning occurred, accounting for $79.8 \%$ of the total number of occurrences. The rest were in medical institutions and during medical treatment.

Univariate conditional logistic regression analysis was performed on 24 influencing factors (Table 3), and possible influencing factors were selected and included in the multivariate conditional logistic regression model (Table 4). The results suggest that the primary caregivers were highly educated, children had full-time care, and children had received unintentional water safety education, which was a protective factor for fatal drowning in children under 5 years. Consistently swimming or playing near the water for the previous 6 months was a risk factor for fatal drowning in children under 5 years .

\section{Discussion}

This study found that the prevalence of fatal drowning in children under 5 years old was 16.1/100,000 in Hunan Province, which was lower than previous studies in Hunan Province [9]. But it was higher than the prevalence of fatal drowning in children under 5 years in Guangdong Province $(10.1 / 100,000)$ [10]. The prevalence of fatal drowning was also higher than the children and adolescents in China determined through meta-analysis $(8.98 / 100,000)$ [11]. This was because drowning usually occurs in early childhood [12]. A population-based cross-sectional study of 32 OECD countries found that: Drowning is a high priority public health problem in Eastern Europe,central Asia,Japan and the USA [13].The government and society should provide a strategic direction and framework for guiding multisectoral actions and evaluate related work.

Males has a greater risk of drowning than females at any location [14], but particularly in pools [15]. This study showed that boys are especially at risk of drowning, nearly with twice the overall mortality rate of girls. It's similar to many other studies [16-18]. Studies have reported that boys are more active and daring [19]. It may be that boys and girls differ in their personality, behavior, cognition and parents educate boys and girls differently about safety.

The majority of drowning events occurred in toddlers aged $0-4$ years, who made up 76 and $72 \%$ of Australian indigenous and non-indigenous drowning incidents, respectively [20].In China, children in the $1-4$ years group are most prone to drowning [21]. This study showed that for drowning, the proportion of children aged 1 to 2 is the highest, which is consistent with the results of a 
Table 2 Epidemic features of fatal drowning in children under 5 years old in Hunan Province

\begin{tabular}{|c|c|c|}
\hline Epidemic features & $\begin{array}{l}\text { Number of } \\
\text { cases (person) }\end{array}$ & $\begin{array}{l}\text { Composition } \\
\text { ratio (\%) }\end{array}$ \\
\hline Total & 79 & \\
\hline \multicolumn{3}{|l|}{ Gender } \\
\hline Male & 51 & 64.6 \\
\hline Female & 28 & 35.4 \\
\hline \multicolumn{3}{|l|}{ Age range (years) } \\
\hline $0 \sim$ & 4 & 5.1 \\
\hline $1 \sim$ & 34 & 43.0 \\
\hline $2 \sim$ & 18 & 22.8 \\
\hline $3 \sim$ & 13 & 16.5 \\
\hline $4 \sim$ & 10 & 12.7 \\
\hline \multicolumn{3}{|l|}{ Season } \\
\hline Spring & 17 & 21.5 \\
\hline Summer & 32 & 40.5 \\
\hline Autumn & 17 & 21.5 \\
\hline Winter & 13 & 16.5 \\
\hline \multicolumn{3}{|l|}{ Address } \\
\hline Urban area & 2 & 2.5 \\
\hline Suburbs & 3 & 3.8 \\
\hline Rural & 74 & 93.7 \\
\hline \multicolumn{3}{|l|}{ Water type village } \\
\hline Open pit & 5 & 6.3 \\
\hline Reservoir & 7 & 8.9 \\
\hline Pond & 37 & 46.8 \\
\hline Ditch & 10 & 12.7 \\
\hline Water tank/bucket & 4 & 5.1 \\
\hline Bathtub & 2 & 2.5 \\
\hline Well & 8 & 10.1 \\
\hline Rivers/Lakes & 3 & 3.8 \\
\hline Dam & 1 & 1.3 \\
\hline Brook & 1 & 1.3 \\
\hline Sewer & 1 & 1.3 \\
\hline \multicolumn{3}{|c|}{ Main activities before the occurrence of drowning } \\
\hline Take a bath & 1 & 1.3 \\
\hline Plying in the water & 4 & 5.1 \\
\hline Playing by the water & 70 & 88.6 \\
\hline Slip when wading & 3 & 3.8 \\
\hline Falling from the upstairs & 1 & 1.3 \\
\hline \multicolumn{3}{|l|}{ Place of death } \\
\hline Where the drowning occurred & 63 & 79.8 \\
\hline Medical institution & 11 & 13.9 \\
\hline On the way to the hospital & 5 & 6.3 \\
\hline \multicolumn{3}{|l|}{ Primary caretaker } \\
\hline Parents & 33 & 41.8 \\
\hline Grandparents and uncles & 43 & 54.4 \\
\hline Neighbors & 3 & 3.8 \\
\hline
\end{tabular}

survey in Jiangsu Province [22]. A possible reason is that children aged 1 to 2 have just learned to walk. They are curious about the surrounding environment and underestimate the danger, and their scope of activity is gradually increased but they lack self-protection abilities. Fatal drowning in children under 5 years in Hunan Province is high in summer, which is the same as in most studies [20,23]. It may be because the summer has high temperatures and abundant rainfall. Children are easily separated from the caretaker and go to the water to play or swim. The proportion of drowning deaths among children in rural areas exceeded $90 \%$, which is consistent with the results of previous surveys in our province [24]. A summary of the drowning incidence in low- and middle-income countries found that of the 4932 cases of drowning, $84 \%$ had died in rural areas with most deaths in Southeast Asian countries [25]. Generally, the low economic levels in rural areas lead to backward infrastructure, unregulated daily management, low education levels of parents, insufficient awareness of drowning, and guardians that are not careful enough to look after the child.

Many countries were found to be failing to report sufficiently codes in drowning mortality data submitted to the WHO [26], which makes it nearly impossible to compare locations and influencing factors between countries. This study shows that the top five water bodies of drowning are ponds, ditches, wells, reservoirs, and open pits. Only a few water bodies have fences or warning signs. Although the occurrence of children's drowning in Guangxi Province [27], Jiangxi Province [28], Jiangsu Province [22] and other places are not the same, drowning cases are mainly concentrated in natural, open waters. In high-income countries, most children's drowning occurs in swimming pools, so installing fences or barriers with automatic closures and self-locking doors is an effective prevention strategy [29]. However, swimming pools are less common in low-income countries, especially in rural areas [19]. In low- and middleincome countries, observational evidence and studies on drowning indicate that natural waters are the greatest risk of drowning in children and that covering open waters or installing fences may be impractical, especially in areas with many nearby waters [30]. Raising public awareness, strengthening health education, strengthening supervision, installing door barriers at the door of the residence, using playpens, or using a fence to designate a safe play area at home or while out is an easy and affordable alternative and a helpful monitor [31-33].

The most prominent activity before fatal drowning in children under 5 years in Hunan Province was playing close to the water. Most of the sudden deaths of children are caused by unintentional exposure to water. In this study, $79.8 \%$ of the drowning cases died at the scene, 
Table 3 Table of assignments of variables

\begin{tabular}{|c|c|}
\hline Variable name & Assignment situation \\
\hline \multirow[t]{2}{*}{ Case control } & $0=$ Control \\
\hline & $1=$ Case \\
\hline \multirow{2}{*}{$\begin{array}{l}\text { the relationship between caretaker and } \\
\text { children }\end{array}$} & $0=$ Father $/$ mother \\
\hline & $1=$ Grandparent \\
\hline \multirow[t]{3}{*}{ Education level of primary caregivers } & $\begin{array}{l}1=\text { Elementary school } \\
\text { and below }\end{array}$ \\
\hline & $2=$ Junior high school \\
\hline & $\begin{array}{l}3=\text { High school and } \\
\text { above }\end{array}$ \\
\hline \multirow[t]{3}{*}{ Smoking status of primary caregivers } & $1=$ Often \\
\hline & $2=$ Occasionally \\
\hline & $3=$ Never \\
\hline \multirow[t]{3}{*}{ Drinking situation of primary caregivers } & $1=$ Often \\
\hline & $2=$ Occasionally \\
\hline & $3=$ Never \\
\hline \multirow[t]{2}{*}{ physical condition of primary caregivers } & $0=$ Health \\
\hline & $1=$ Sick \\
\hline Are there other children in the family? & $0=$ No $1=$ Yes \\
\hline Is it a left-behind child? & $0=$ No $1=$ Yes \\
\hline Total annual income of the family & $\begin{array}{l}1=<20,0002= \\
20,000 \sim 79,9993=\geq 80,000\end{array}$ \\
\hline $\begin{array}{l}\text { Is there a water storage container in the } \\
\text { house? }\end{array}$ & $0=$ No $1=$ Yes \\
\hline \multirow[t]{3}{*}{ Whether the container holds water } & $1=$ Often \\
\hline & $2=$ Occasionally \\
\hline & $3=$ Never \\
\hline Whether the container has a lid or fence & $0=$ No $1=$ Yes \\
\hline $\begin{array}{l}\text { Is there a water body near the place of } \\
\text { residence? }\end{array}$ & $0=$ No $1=$ Yes \\
\hline Whether the water body has a lid or fence & $0=$ No $1=$ Yes \\
\hline $\begin{array}{l}\text { Is there a medical institution within } 500 \mathrm{~m} \\
\text { of the current residence? }\end{array}$ & $0=$ No $1=$ Yes \\
\hline Does the child have full-time care? & $0=$ No $1=$ Yes \\
\hline \multirow{2}{*}{$\begin{array}{l}\text { Father's time spent with children in the last } \\
\text { month }\end{array}$} & $1=<7 \mathrm{~h} 2=7 \sim 20 \mathrm{~h}$ \\
\hline & $3=21 \sim 34 h \quad 4=\geq 35 h$ \\
\hline \multirow{2}{*}{$\begin{array}{l}\text { Mother's time spent with children in the } \\
\text { last month }\end{array}$} & $1=<7 \mathrm{~h} 2=7 \sim 20 \mathrm{~h}$ \\
\hline & $3=21 \sim 34 \mathrm{~h} 4=\geq 35 \mathrm{~h}$ \\
\hline \multirow{2}{*}{$\begin{array}{l}\text { The most common way to take a bath for } \\
\text { children in the past month }\end{array}$} & $0=$ bathtub \\
\hline & $1=$ take a shower \\
\hline \multirow[t]{3}{*}{ Caregiver swimming ability } & $1=$ can not swim \\
\hline & $2=$ not very skilled \\
\hline & $3=$ skilled \\
\hline $\begin{array}{l}\text { Caregivers think that children should be } \\
\text { taught to swim }\end{array}$ & $0=$ No $1=$ Yes \\
\hline Has the caregiver taught children to swim? & $0=$ No $1=$ Yes \\
\hline \multirow{2}{*}{$\begin{array}{l}\text { Have children ever swum or played by the } \\
\text { water in the past } 6 \text { months? }\end{array}$} & 1 = Often \\
\hline & $2=$ Occasionally \\
\hline
\end{tabular}

Table 3 Table of assignments of variables (Continued)

\begin{tabular}{ll}
\hline Variable name & Assignment situation \\
\hline $\begin{array}{l}\text { Whether the caregiver has the emergency } \\
\text { rescue knowledge of drowning }\end{array}$ & $0=$ No $1=$ Yes \\
$\begin{array}{l}\text { Has the child }(\geq 1 \text { year) received safety } \\
\text { education for unintentional drowning? }\end{array}$ & $0=$ No $1=$ Yes \\
\hline
\end{tabular}

and $6.3 \%$ died on the way to medical treatment. In Suzhou [34], more than half of children under the age of 5 years cannot receive timely treatment after drowning. In Haimen [35], 90.9\% of child fatalities from drowning occurred in their homes or on their way to hospital. The reason for this phenomenon is as follows: first, the caretaker's poor supervision means they cannot find the children that have fallen into the water in time; second, the rural areas are underdeveloped, so it is difficult to get drowning children to the hospital in time; and third, many people do not have the skills to perform cardiopulmonary resuscitation. Although rescue and recovery have a limited impact on reducing drowning mortality and incidence, in the event of drowning, rescue and recovery can determine whether a person lives or dies [36].

Multivariate conditional logistic regression analysis indicated that a high level of education of the primary caregiver was a protective factor for the occurrence of fatal drowning in children under 5 years in Hunan Province. Some studies [37] note that the cultural level of caregivers affects the occurrence of drowning in rural children and that children in families with lower education levels are at greater risk of fatal drowning. The survey found that the main caregivers of children under 5 years are grandparents who have low levels of education, lack safety awareness, common sense and knowledge about drowning, also poorly supervise children. Fulltime nursery care is a protective factor for the occurrence of fatal drowning in children under 5 years. A number of investigations have shown that children are prone to drowning accidents when caregivers neglect them [25, 38]. Unintentional drowning safety education for children is a protective factor for fatal drowning in children under 5 years of age. Some studies [39] have indicated that caregivers sometimes/often inform children that safety knowledge is a factor in drowning protection. The main caregivers should strengthen their safety education regarding children's contact with water, especially in outdoor waters. Swimming or playing near the water in the past 6 months was a risk factor for fatal drowning, which was similar to other studies $[38,40]$. Children like to play with water; their cognitive functional development is not perfect, and they lack sufficient awareness of the dangerous environment. Therefore, when they play, swim or wash things at the water's edge, they are prone to falling into the water, leading to death. 
Table 4 Multi-factor conditional logistic regression analysis of fatal drowning in children under 5 years old in Hunan Province

\begin{tabular}{|c|c|c|c|c|c|c|}
\hline Influencing factor & $\beta$ & $S_{b}$ & Wald $x^{2}$ & $P$ & $O R$ & $90 \% C /(\%)$ \\
\hline \multicolumn{7}{|c|}{ Education level of primary caregivers } \\
\hline Elementary school and below & & & & & 1.00 & \\
\hline Junior high school & -1.58 & 0.61 & 6.75 & $<0.01$ & 0.21 & $0.08-0.56$ \\
\hline High school and above & -3.07 & 1.07 & 8.28 & $<0.01$ & 0.05 & $0.01-0.27$ \\
\hline \multicolumn{7}{|c|}{ Does the child have full-time care? } \\
\hline No & & & & & 1.00 & \\
\hline Yes & -1.75 & 0.68 & 6.71 & 0.01 & 0.17 & $0.06-0.53$ \\
\hline \multicolumn{7}{|c|}{ Have children ever swimming or playing by the water in the past 6 months? } \\
\hline Never & & & & & 1.00 & \\
\hline Occasionally & 0.98 & 1.05 & 0.88 & 0.35 & 2.67 & $0.48-15.02$ \\
\hline Often & 1.14 & 0.54 & 4.49 & 0.03 & 3.13 & $1.29-7.60$ \\
\hline \multicolumn{7}{|c|}{ Has the child ( $\geq 1$ year)received safety education for unintentional drowning? } \\
\hline No & & & & & 1.00 & \\
\hline Yes & -1.46 & 0.70 & 4.32 & 0.04 & 0.23 & $0.07-0.74$ \\
\hline
\end{tabular}

The exposure level of a dangerous environment is an important factor in determining whether sudden death can occur [41].

However, there are still some limitations in this study. Firstly, the survey questionnaires involved individuals, family privacy and some situations when drowning occurred. Some children caregivers were at work or refused an investigation, or were unwilling to answer the sensitive questions, which may affect the representativeness of the sample. Secondly, consider that the family members' emotions and acceptance, local customs, organizational coordination, etc. There was a time interval between the time of the questionnaire and the occurrence of drowning, and it was difficult to avoid recall bias of the respondents during the investigation. Third, the disadvantage of cluster sampling is that the sampling error caused by cluster sampling is often larger than that of simple random sampling because of the great difference between different groups. Based on the above limitations, the scope of the research, the survey area, the credibility of respondents and the extrapolation of the results can be expanded in future research.

\section{Conclusion}

Drowning is an important cause of injury-related death, also in Hunan province. Fatal drowning incidence of children under 5 years in Hunan province is presented for the first time. The quality of data from this study identifies risk factors and gives good insight for interventions to target specific sociodemographic, age and gender groups. Rural areas are the main areas of drowning. Ponds, ditches and wells dominate the drowning burden for under 5 years and produced the most fatalities. Most drowning occurred because of playing near the water. Therefore, more communities should implement day care to ensure continued adult supervision, especially during the day. In addition, small ponds and irrigation ditches should be fenced or drained, and ponds/Wells should be covered with grates to prevent children from falling into them. Finally, all of the risk factors of drowning should be taken into account when designing preventive measures and family education. These preventative strategies are especially important in rural areas where the risks of drowning are higher.

\section{Acknowledgments}

We acknowledge each of the data custodians for assistance in acquiring data. We acknowledge those local people who self-identified and made this study possible. Special thanks go to professor Shuai Chen (Associate Professor of Biostatistics, University of California School of Public Health), and Professor Guibo Xing(statistician at the Center for Medical Policy and Research),for their advices and guidance on this article's statistical methods during my clinical observation at UC Davis Medical center.

\section{Author's contributions}

$Z \mathrm{~L}, \mathrm{~F} \mathrm{~K}, \mathrm{~A}$ W and $\mathrm{L} X$ participated in the design of the study and data collection. $Z L$ and $L Y$ performed the statistical analysis. $Z L, F K, L Y, A$ W, $L X$ $D X, L C$ and $X S$ conceived of the study and participated in its design as well as coordination and helped to write and revise the manuscript. All authors read and approved the final manuscript.

\section{Funding}

Funding support received from Hunan Science and Technology Innovation Project (2017SK50802). The funding agency did not affect the design of research, the collection, analysis and interpretation of data, or the writing of papers.

Availability of data and materials

The datasets used and/or analysed during the current study are available from the corresponding author on reasonable request.

Competing interest

The authors declare that they have no competing interests. 


\section{Ethics approval and consent to participate}

Ethics and approvals were sought and granted from West China Second University Hospital SiChuan University(Approval for ethical review of biomedical research involving humans,2010-015), and obtained the written informed consent of all the participants. Participation of subjects was voluntary and written consent was obtained from all participants prior to data collection.

\section{Consent for publication}

Not Applicable.

\section{Author details}

'Information Management Division, Hunan Provincial Maternal and Child Health Care Hospital, Changsha, Hunan Province, China. ${ }^{2}$ Hunan Provincial Center for Disease Control and Prevention, Changsha, Hunan Province, China. ${ }^{3}$ Department of Epidemiology and Health Statistics, Xiangya School of Public Health, Central South University, Changsha, Hunan Province, China. ${ }^{4}$ Hunan Provincial Maternal and Child Health Care Hospital, Changsha, Hunan Province, China.

\section{Received: 14 March 2019 Accepted: 26 June 2019}

Published online: 17 July 2019

\section{References}

1. Global report on drowning: preventing a leading killer. 2014 World Health Organization.

2. Salas B A, de Carlos Vicente J C, Juan FG, et al..Prognostic Factors of Children Admitted to a Pediatric Intensive Care Unit After an Episode of Drowning[J].Pediatric Emergency Care .2018;0(0): 00-00. www.peconline.com

3. Naira $H$, Byassbc P. Mortality in older children and adolescents: the forgotten ones[J]. Lancet Child Adolesc Health. 2018;2(5):306-307. https:// doi.org/10.1016/S2352-4642(18)30067-1.

4. Imamura JH, Troster EJ, Oliveira CA. What types of unintentional injuries kill our children? Do infants die of the same types of injuries? A systematic review[J]. Clinics. 2012;67(9):1107-16. 23018311. https://doi.org/10.6061/ clinics/2012(09)20.

5. Ye $P, Y e J$, Yuliang $E_{\text {, et }}$ al. Disease burden of injuries in children aged 0-14year-old in 1990and 2013,in China[J]. Chin J Epidemiol. 2017;38(10):1335-41. https://doi.org/10.3760/cma.j.issn.0254-6450.2017.10.008.

6. Guo QZ, Ma WJ. Drowning and its prevention[J]. Chin J Epidemiol. 2009; 30(12):1311-4. https://doi.org/10.3760/cma.j.issn.0254-6450.2009.12.025

7. Lili $X$, Jian $H$, Liping $L$, et al. Epidemiology of injury-related death in children under 5 years of age in Hunan Province, China, 2009-2014[J]. PLoS One. 2017;12(1):e0168524. https://doi.org/10.1371/journal.pone.0168524.

8. Li N, Qin JB, Yang F. Analysis of mortality among children under 5 years old in Hunan in 2013[J]. J Cent South Univ: Med Sci. 2016:41(3):287-94. https:// doi.org/10.11817/j.issn.1672-7347.2016.03.010.

9. Liu JH, Huang GW. Mortality rate and causes of death among children below 5 years old in Hunan Province, 2009-2014[J]. Pract Prev Med. 2016;(1): 72-5. https://doi.org/10.3969/j.issn.1006-3110.2016.01.021.

10. Meng RL, Xu YJ, Xu HF, et al. Epidemiological characteristics on fatal injury among child in Guangdong Province[J]. Chin J Sch Health. 2013;34(11): 1356-8. https://doi.org/10.16835/j.cnki.1000-9817.2013.11.028.

11. Li ML. Disease burden of injuries among children and adolescents in China: a systematic review[D]. Taiyuan: Shanxi Medical University, 2014

12. Zhao W. Investigation and analysis of 5645 cases of children's unintentional injuries[D]. Lanzhou: Ningxia Medical University; 2016.

13. Hsieh W-H,Wang C-H, Lu T-H. Drowning mortality by intent: a populationbased cross-sectional study of 32 OECD countries, 2012-2014. BMJ Open. 2018:8:e021501. https://doi.org/10.1136/bmjopen-2018-021501.

14. Sarrassat S, Mrema S, Tani K, et al. Estimating drowning mortality in Tanzania: a systematic review and meta-analysis of existing data sources. Injury Prevention. 2018;0:1-13. https://doi.org/10.1136/injuryprev-2018-042939.

15. Peden AE, Mahony AJ, Barnsley PD, et al. Understanding the full burden of drowning: a retrospective, cross-sectional analysis of fatal and non-fatal drowning in Australia[J]. BMJ Open. 2018;8(11):e024868. https://doi.org/10. 1136/bmjopen-2018-024868.

16. Wallis $\mathrm{BA}$, Watt $\mathrm{K}$, Franklin $\mathrm{RC}$, et al. Drowning mortality and morbidity rates in children and adolescents 0-19yrs: a population-based study in
Queensland, Australia[J]. PLoS One. 2015;10(2):e0117948. https://doi.org/10. 1371/journal.pone.0117948

17. Lunetta P, Smith GS, Penttila A, et al. Unintentional drowning in Finland 1970-2000: a population-based [J]. Int J Epidemiol. 2004;33(5):1053-63. https://doi.org/10.1093/ije/dyh194.

18. Giizel A, Duran L, Paksu S, et al. Drowning and near-drowning: experience of a university in the Black Sea region [J]. Turk J Pediatr. 2013;55(6):620-7 https://www.researchgate.net/publication/260431055.

19. Yang L, Nong QQ, Li C, et al. Risk factors for childhood drowning in rural regions of a developing country: a case-control study[J]. Inj Prev. 2007;13(3): 178-82. 17567973. https://doi.org/10.1136/ip.2006.013409.

20. Wallis BA, Watt K, Franklin RC, et al. Drowning in aboriginal and Torres Strait islander children and adolescents in Queensland(Australia) [J]. BMC Public Health. 2015;19(15):795-805. https://doi.org/10.1186/s12889-015-2137-z.

21. Sun YY, LV CH, Wang WW, et al. Analysis on research status of childhood unintentional injury[J]. Chin J Rehabil Theory Pract. 2014;20(2):176-9. https:// doi.org/10.3969/j.issn.1006-9771.2014.02.020.

22. Zhang PB, Deng JY, Chen RH, et al. Analysis on the causes of accidental suffocation and drowning among children aged 0 4 in countryside of Jiangsu[J]. Chin J Dis Control Prev. 2001;5(3):243-4.

23. Gu JY. Wuxi city from 2004 to 2013 children under the age of five accidental death[D]. Suzhou: Suzhou University; 2015.

24. Liu WQ. The analysis and responses of drowning accidents of primary and secondary school students in Hunan rural area[D]. Xiangtan: Hunan University of Science and Technology, 2016.

25. Tyler MD, Richards DB. Reske-NielsenC, et al. the epidemiology of drowning in low-and middle-income countries: a systematic review[J]. BMC Public Health. 2017;17(1):413-9. https://doi.org/10.1186/s12889-017-4239-2.

26. Lu T-H, Lunetta P, Walker S. Quality of cause-of-death reporting using ICD10 drowning codes: a descriptive study of 69 countries. BMC Med Res Methodol. 2010;10(30). https://doi.org/10.1186/1471-2288-10-30.

27. Nong QX, Yang L. Analysis on drowning among children in rural areas of Guangxi Province[J]. Chin J Public Health. 2006;22(9):1043-4. https://doi.org/ 10.3321/j.issn:1001-0580.2006.09.012.

28. Ji L, Zhu LP, Yan W, et al. Analysis of drowning death among children aged 1-17 years in Jiangxi Province[J]. Jiangxi Medical Journal. 2011;46(2):182-4. https://doi.org/10.3969/j.issn.1006-2238.2011.02.049.

29. Wallis BA, Watt $K$, Franklin $\mathrm{RC}$, et al. Where children and adolescents drown in Queensland: a population-based study[J]. BMJ Open. 2015;5(11):e008959. https://doi.org/10.1136/bmjopen-2015-008959.

30. labal A, Shirin T, Ahmed T, et al. Childhood mortality due to drowning in rural Matlab of Bangladesh: magnitude of the problem and proposed solutions[J]. J Health Popul Nutr. 2007;25(3):370-6. 18330071.

31. Hyder $\mathrm{AA}$, Alonge $\mathrm{O}, \mathrm{He} \mathrm{S}$, et al. A framework for addressing implementation gap in global drowning prevention interventions: experiences from Bangladesh[J]. J Health Popul Nutr. 2014;32(4):564-76. 25895188.

32. Hyder AA, Alonge $\mathrm{O}, \mathrm{He} \mathrm{S}$, et al. Saving of children's lives from drowning project in Bangladesh[J]. Am J Prev Med 2014;47(6):842-845. DOl: https:// doi.org/10.1016/j.amepre.2014.07.050, PMID: 25241200

33. Ramos W, Beale A, Chambers $P$, et al. Primary and secondary drowning interventions: the American red Cross circle of drowning prevention and chain of drowning survival[J]. International Journal of Aquatic Research and Education. 2015;9(1):89-101. https://doi.org/10.25035/ijare.09.01.08.

34. Wu QL, Wang J, Xu QH, et al. Analysis of the drowning death among children under 5 years old in Suzhou during 2006-2010[J]. Nei Mongol Journal of Traditional Chinese Medicine. 2012;(6):64-5. https://doi.org/10. 3969/j.issn.1006-0979.2012.06.067.

35. Wang XQ. Analysis of drowning in children aged $1 \sim 4$ years in Haimen in 1996-2000[J]. Sh J Prev Med. 2003;15(11):579-80. https://doi.org/10.19428/j. cnki.sjpm.2003.11.033.

36. Hossain M, Mani KK, Sidik SM, et al. Socio-demographic, environmental and caring risk factors for childhood drowning deaths in Bangladesh[J]. Biomed Central Pediatrics. 2015;1(5):114-9. https://doi.org/10.1186/s12887-015-0431-7.

37. Chen XX, Dai L, Fang Y. Epidemiological investigation and risk factors of accidental drowning among 1 14 year old children in rural Xiamen[C]. Compilation of the 10th anniversary of the East China epidemiology conference and the 20th anniversary of the East China epidemiology conference. Hefei,2010: 607-609.

38. Guo QZ, Xu HF, Song XL, et al. Case-control study on risk factors for nonfatal drowning in rural areas[J]. Chin J Sch Health. 2010:31(2):200-3. https:// doi.org/10.16835/j.cnki.1000-9817.2010.02.036. 
39. Tao X. A case-control study on the influencing factors for injury among the rural school-aged children in Jianshi County of Enshi[D]. Wuhan: Wuhan University of Science and Technology; 2016.

40. Yang L, Nong QX, Li CL, et al. A case-control study on risk factors of drowning among children aged between 1 and 14 in rural areas of Guangxi[]]. Chin J Epidemiol. 2006;27(10):853-6. https://doi.org/10.3760/j. issn:0254-6450.2006.10.007

41. Gulliver P, Begg D. Usual water-related behaviour and'near-drowning' incidents in young adults[]]. Aust N Z J Public Health. 2005;29(3):238-43. https://doi.org/10.1111/j.1467-842X.2005.tb00761.X.

\section{Publisher's Note}

Springer Nature remains neutral with regard to jurisdictional claims in published maps and institutional affiliations.

Ready to submit your research? Choose BMC and benefit from:

- fast, convenient online submission

- thorough peer review by experienced researchers in your field

- rapid publication on acceptance

- support for research data, including large and complex data types

- gold Open Access which fosters wider collaboration and increased citations

- maximum visibility for your research: over $100 \mathrm{M}$ website views per year

At $\mathrm{BMC}$, research is always in progress.

Learn more biomedcentral.com/submissions 